\title{
Optimization of Bending Process Parameters for Seamless Tubes Using Taguchi Method and Finite Element Method
}

\author{
Jui-Chang $\operatorname{Lin}^{1}$ and Kingsun Lee ${ }^{2}$ \\ ${ }^{1}$ Department of Mechanical Design Engineering, National Formosa University, Yunlin 632, Taiwan \\ ${ }^{2}$ Department of Mechanical Engineering, Chienkuo Technology University, Changhua 500, Taiwan \\ Correspondence should be addressed to Kingsun Lee; kingsun@ctu.edu.tw
}

Received 29 September 2014; Accepted 15 April 2015

Academic Editor: Hiroshi Noguchi

Copyright (c) 2015 J.-C. Lin and K. Lee. This is an open access article distributed under the Creative Commons Attribution License, which permits unrestricted use, distribution, and reproduction in any medium, provided the original work is properly cited.

\begin{abstract}
The three-dimensional tube (or pipe) is manufactured by CNC tube bending machine. The key techniques are determined by tube diameter, wall thickness, material, and bending radius. The obtained technique through experience and the trial and error method is unreliable. Finite element method (FEM) simulation for the tube bending process before production can avoid wasting manpower and raw materials. The computer-aided engineering (CAE) software ABAQUS 6.12 is applied to simulate bending characteristics and to explore the maximum stress and strain conditions. The Taguchi method is used to find the optimal parameters of bending. The confirmation experiment is performed according to optimal parameters. Results indicate that the strain error between CAE simulation and bending experiments is within $6.39 \%$.
\end{abstract}

\section{Introduction}

In the mechanical manufacturing industry, tube bending is very commonly used in processing and its products are widely applied in major industries, such as power plants, aviation, petrochemical industry, and the boiler industry.

The bending process for thin wall tubes is often a technical issue. The basic parameters of the copper elbow bending process include the bending moment, the type and degree of deformation of cross section, and change of the wall thickness. The axial upsetting force on the above mentioned parameters was applied to improve problems associated with the changes of wall thickness [1].

Tubes subjected to a point load result in local oval forming which influences tube strength. Oval forming and the flattening effect of tubes experienced during bending was first researched by Brazier and therefore was called the Brazier effect [2]. An increase in internal pressure, together with a point load condition, results in a change to sectional properties of the tube, thus leading to bending of the tube and ultimately structural failure.
Shaw and Kyriakides [3,4] experimentally tested the response and stability of elastoplastic pipes under combined bending and external pressure. They designed a small lightweight instrument, which can be used to measure the change in the diameter of the tube at a point in the plane of bending. The same instrument is used to experimentally measure the ovalization of inelastic tubes under cyclic bending. They demonstrated that reverse bending and subsequent repeated cyclic bending cause a gradual growth of the ovalization of the tube's cross section. They further extended their experimental program to investigate the stability of thinwalled tubes under cyclic bending. The results indicated that, under curvature-symmetric loading, the tube progressively ovalizes to a critical value at which point it buckles.

Vollertsen et al. [5] gave a systematic overview about the existing processes for the bending of extrusions in both small and large scale production. Some of the important features of working accuracy in bending extrusions were reviewed. This included the accuracy of the curvature and deviations in the cross section. Methods of open- and closed-loop control based on process modeling for increased accuracy 
were shown as well as practical methods to avoid cross section deformation.

For pipe bends subjected to out-of-plane bending, the addition of torsional effects makes it more complex to estimate the plastic collapse moment. The collapse moment is reached first at a section around the middle of the bend part. Mourad and Younan $[6,7]$ performed an analysis to evaluate the behavior of a pipe bend subjected to out-of-plane bending and internal pressure. They showed that the loaded end of the bend was the most severely strained cross section and found that considerable plastic deformation occurred before instability was reached, especially in the presence of applied pressure.

Cross section ovalization is one of the flaws in the thin-walled tube NC bending process. A unique quality estimator of the cross section geometry of bent tubes has been developed, which is able to synthetically represent the main functional and aesthetical properties of tubes. The deformation occurring in the cross section of the tube has been studied through a set of FEM simulations, run with an explicit code with shell elements. The model has been validated by comparing the experimental and numerical results of specific cases in terms of geometry of the cross section in a $90^{\circ}$ bend. A proposed indicator is able to reliably estimate the difficulty of a bending process with respect to a tendency towards ovalization and collapse of the cross section [8].

Much research, using FEM and experiments, has been carried out on the thin-walled tube bending processes. The stress and strain distribution, tube wall thinning, cross section ovalization, and other defects in the NC bending have been studied [9]. The finite element method (FEM) is a useful tool for optimizing the process layout in metal forming. Numerical simulation helps designers to estimate metal formability and improve process layout.

In this study, the computer-aided engineering (CAE) software ABAQUS applied finite element method (FEM) to simulate bending characteristics and to explore the maximum stress and strain conditions. The Taguchi method was used to find the optimal parameters of bending forming. The confirmation experiment using strain gauge was performed according to optimal parameters. The results indicate that the CAE precisely simulated the bending experiment.

\section{Elastoplastic Analysis}

If an elastoplastic deformable body is in dynamic equilibrium state, the following force balance equation (1) and boundary conditions (2) are established for every material point which is covered in $\Omega$ of the body:

$$
\begin{aligned}
& \rho \ddot{u}_{i}=\sigma_{j i, j}+\rho b_{i} \quad \text { in } \Omega, \\
& t_{i}=-h_{i j}\left(u_{j}-g_{j}\right)+f_{j} \quad \text { on } \Gamma=\Gamma_{u}+\Gamma_{F}+\Gamma_{c}, \\
& h_{i j}= \begin{cases}K \delta(K \longrightarrow \infty), & \text { on } \Gamma_{u}, \\
0, & \text { on } \Gamma_{F}\end{cases}
\end{aligned}
$$

where $\rho=$ material density, $u_{i}=$ displacement vector, $\sigma_{i j}=$ Cauchy stress tensor $b_{i}=$ body force vector, $t_{i}=$ drag force vector on the body surface, $K=$ spring constant, $g_{i}=$ known displacement vector on the displacement boundary $\Gamma_{u}, f_{i}=$ known load vector on the load boundary $\Gamma_{F}$, and $\Gamma_{c}=$ mixed boundary, the sum of $\Gamma_{u}$ and $\Gamma_{F}$.

Principle of virtual work, finite element, and numerical integration are applied to derive the following nonlinear differential equation:

$$
[M]\{\ddot{u}\}+[C]\{\dot{u}\}+[K]\{u\}=\{P\},
$$

where $[M]=$ total mass matrix, $[C]=$ total damping matrix, $[K]=$ total stiffness matrix, and $\{P\}=$ total load vectors.

\section{Design of Experiments}

The Taguchi method was created by Genichi Taguchi in 1949. It is an engineering methodology for obtaining the relationship between products and the manufacturing process.

The Taguchi method is an important tool for robust design, combining experimental design theory and the concept of quality loss function. It offers a simple and systematic approach to optimize performance design, quality, and cost [10-12].

Taguchi's approach is based on statistical design of experiments, which fulfills the requirements to solve engineering problems and enhance process optimization. Taguchi suggests analyzing variation using an appropriately chosen signal-to-noise ratio $(S / N)$. These $S / N$ ratios are derived from the quadratic loss function. The Taguchi analysis of the $S / N$ ratio involves three kinds of quality characteristic, including the-nominal-the-better, the-smaller-the-better, and the-larger-the-better. To obtain optimal bending performance, the-smaller-the-better quality characteristic for minimizing maximum stress and strain must be taken. It can be expressed as

$$
\frac{S}{N}=-10 \log \left(\frac{1}{n} \sum_{i=1}^{n} y_{i}^{2}\right),
$$

where $y_{i}$ is the observed data. Regardless of category, $n$ is the number of experiments in a trial. A greater $S / N$ ratio corresponds to a better performance. The level of a factor with the highest signal-to-noise ratio is the optimum level [13].

In this study, the finite element analysis combined with Taguchi methods $\mathrm{L}_{18}\left(2^{1} \times 3^{7}\right)$ orthogonal array was used to simulate the bending process of three-dimensional seamless pipe. Table 1 represents experimental factors and their levels. Table 2 is the orthogonal array. CAE software ABAQUS was applied to simulate bending according to orthogonal array. The optimal bending process parameters were obtained via $S / N$ ratio analysis. Finally, the confirmation experiment was performed to verify the consistency between the simulation and the actual bending process.

In practical three-dimensional bending process, $\mathrm{CNC}$ tube bending process was illustrated in Figures 1 and 2. $Y$ axis was the feed direction of the tube; $B$-axis was the rotation direction of the tube along its axis, and $C$-axis was bending 
TABLE 1: Control factors and levels.

\begin{tabular}{llccc}
\hline & Factors & \multicolumn{3}{c}{ Levels } \\
& & 1 & 2 & 3 \\
\hline A & Feed axis $Y$ strokes 1, 2 & $135 \mathrm{~mm}$ & $140 \mathrm{~mm}$ & - \\
B & Feed axis $Y$ stroke 3 & $110 \mathrm{~mm}$ & $115 \mathrm{~mm}$ & $120 \mathrm{~mm}$ \\
C & Rotation axis B stroke 1 & $-245^{\circ}$ & $-250^{\circ}$ & $-255^{\circ}$ \\
D & Rotation axis B stroke 2 & $-225^{\circ}$ & -230 & $-235^{\circ}$ \\
E & Rotation axis B stroke 3 & $-75^{\circ}$ & $-80^{\circ}$ & $-85^{\circ}$ \\
F & Bending axis C stroke 1 & $45.5^{\circ}$ & $46^{\circ}$ & $46.5^{\circ}$ \\
G & Bending axis C stroke 2 & $46.5^{\circ}$ & $47^{\circ}$ & $47.5^{\circ}$ \\
H & Bending axis C stroke 3 & $48^{\circ}$ & $48.5^{\circ}$ & $49^{\circ}$ \\
\hline
\end{tabular}

TABLE 2: Orthogonal array $\mathrm{L}_{18}\left(2^{1} \times 3^{7}\right)$.

\begin{tabular}{lcccccccc}
\hline Sets number & $\mathrm{A}$ & $\mathrm{B}$ & $\mathrm{C}$ & $\mathrm{D}$ & $\mathrm{E}$ & $\mathrm{F}$ & $\mathrm{G}$ & $\mathrm{H}$ \\
\hline 1 & 1 & 1 & 1 & 1 & 1 & 1 & 1 & 1 \\
2 & 1 & 1 & 2 & 2 & 2 & 2 & 2 & 2 \\
3 & 1 & 1 & 3 & 3 & 3 & 3 & 3 & 3 \\
4 & 1 & 2 & 1 & 1 & 2 & 2 & 3 & 3 \\
5 & 1 & 2 & 2 & 2 & 3 & 3 & 1 & 1 \\
6 & 1 & 2 & 3 & 3 & 1 & 1 & 2 & 2 \\
7 & 1 & 3 & 1 & 2 & 1 & 3 & 2 & 3 \\
8 & 1 & 3 & 2 & 3 & 2 & 1 & 3 & 1 \\
9 & 1 & 3 & 3 & 1 & 3 & 2 & 1 & 2 \\
10 & 2 & 1 & 1 & 3 & 3 & 2 & 2 & 1 \\
11 & 2 & 1 & 2 & 1 & 1 & 3 & 3 & 2 \\
12 & 2 & 1 & 3 & 2 & 2 & 1 & 1 & 3 \\
13 & 2 & 2 & 1 & 2 & 3 & 1 & 3 & 2 \\
14 & 2 & 2 & 2 & 3 & 1 & 2 & 1 & 3 \\
15 & 2 & 2 & 3 & 1 & 2 & 3 & 2 & 1 \\
16 & 2 & 3 & 1 & 3 & 2 & 3 & 1 & 2 \\
17 & 2 & 3 & 2 & 1 & 3 & 1 & 2 & 3 \\
18 & 2 & 3 & 3 & 2 & 1 & 2 & 3 & 1 \\
\hline
\end{tabular}

direction of the tube which was bent by wiper die. Three form blocks were fixed and axis of seamless tube were fixed. In accordance with the design parameters of the Taguchi method wiper die was rotated along bending axis of the tube while tube rotated and fed itself to complete $Y, B$, and $C$ three strokes.

The material used in this experiment was the seamless SUS-304 stainless steel tube with corrosion resistance, high strength, electrical conductivity, and good mechanical properties (Table 3); its maximum stress was $626 \mathrm{MPa}$ and maximum strain was 0.42 . This experimental tube had a length of $800 \mathrm{~mm}$, an inner diameter of $34 \mathrm{~mm}$, and a wall thickness of $1.5 \mathrm{~mm}$.

\section{Results and Discussions}

The maximum stresses and strains were obtained by ABAQUS simulation analysis. Eighteen data sets are listed in

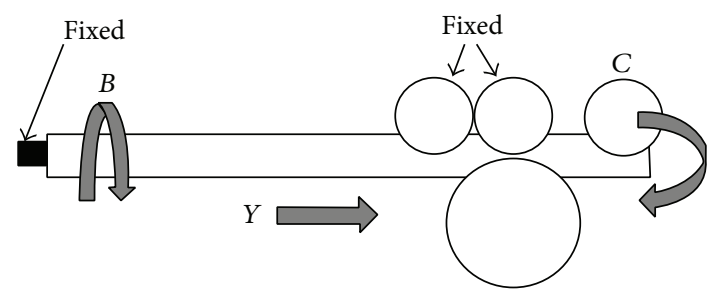

FIgURE 1: Three control factors.

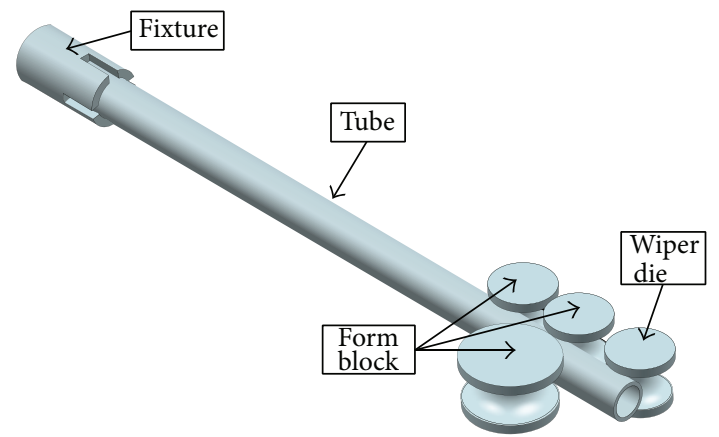

FIGURE 2: Tube bending configuration.

TABLE 3: Mechanical properties of typical 304 stainless steel.

\begin{tabular}{lc}
\hline Density $\left(\mathrm{kg} / \mathrm{mm}^{3}\right)$ & 0.789 \\
Poisson's ratio & 0.33 \\
Young's modulus (Gpa) & 190 \\
Yield strength (Mpa) & 296 \\
Ultimate strength (Mpa) & 626 \\
Ultimate strain & 0.42 \\
\hline
\end{tabular}

Table 4. Set numbers 2 and 12 in Table 4 show that maximum stresses were very close to the tensile strength of material SUS-304 (626 MPa). Set numbers 13 and 18 of plastic strain also exceeded the maximum strain (0.42). Thus, these four sets of bending pipe will be broken.

The experimental results were then transformed into a signal-to-noise $(S / N)$ ratio. Taguchi recommends the use of the $S / N$ ratio to measure quality characteristics. A greater $S / N$ ratio corresponds to improved quality. In this study, the-lower-the-better quality characteristic (5) was used to calculate the $S / N$ ratio for maximum stress and strain and the results are listed in Table 5 .

Table 6 represents the $S / N$ ratio at each level of all control factors for strain. The effect of the control factor was determined by its level of difference values. A larger control factor level difference resulted in a greater effect on strain in the bending process. Figure 3 shows the $S / N$ response graph for strain. 
TABLE 4: Stress and strain of FEM simulation.

\begin{tabular}{|c|c|c|c|c|c|c|c|c|c|c|}
\hline Sets number & A & B & $\mathrm{C}$ & $\mathrm{D}$ & $\mathrm{E}$ & $\mathrm{F}$ & G & $\mathrm{H}$ & $\begin{array}{c}\text { Maximum stress } \\
(\mathrm{MPa})\end{array}$ & $\begin{array}{c}\text { Maximum strain } \\
(\mathrm{mm} / \mathrm{mm})\end{array}$ \\
\hline 1 & 1 & 1 & 1 & 1 & 1 & 1 & 1 & 1 & 433.7 & 0.2978 \\
\hline 2 & 1 & 1 & 2 & 2 & 2 & 2 & 2 & 2 & 612.2 & 0.4075 \\
\hline 3 & 1 & 1 & 3 & 3 & 3 & 3 & 3 & 3 & 459.3 & 0.3607 \\
\hline 4 & 1 & 2 & 1 & 1 & 2 & 2 & 3 & 3 & 479.6 & 0.3108 \\
\hline 5 & 1 & 2 & 2 & 2 & 3 & 3 & 1 & 1 & 493.5 & 0.3183 \\
\hline 6 & 1 & 2 & 3 & 3 & 1 & 1 & 2 & 2 & 549.0 & 0.3688 \\
\hline 7 & 1 & 3 & 1 & 2 & 1 & 3 & 2 & 3 & 444.4 & 0.3056 \\
\hline 8 & 1 & 3 & 2 & 3 & 2 & 1 & 3 & 1 & 588.0 & 0.3238 \\
\hline 9 & 1 & 3 & 3 & 1 & 3 & 2 & 1 & 2 & 475.5 & 0.4091 \\
\hline 10 & 2 & 1 & 1 & 3 & 3 & 2 & 2 & 1 & 452.3 & 0.4114 \\
\hline 11 & 2 & 1 & 2 & 1 & 1 & 3 & 3 & 2 & 465.5 & 0.2996 \\
\hline 12 & 2 & 1 & 3 & 2 & 2 & 1 & 1 & 3 & 625.1 & 0.3768 \\
\hline 13 & 2 & 2 & 1 & 2 & 3 & 1 & 3 & 2 & 508.7 & 0.4941 \\
\hline 14 & 2 & 2 & 2 & 3 & 1 & 2 & 1 & 3 & 491.4 & 0.3253 \\
\hline 15 & 2 & 2 & 3 & 1 & 2 & 3 & 2 & 1 & 463.2 & 0.3031 \\
\hline 16 & 2 & 3 & 1 & 3 & 2 & 3 & 1 & 2 & 457.6 & 0.3021 \\
\hline 17 & 2 & 3 & 2 & 1 & 3 & 1 & 2 & 3 & 471.2 & 0.2995 \\
\hline 18 & 2 & 3 & 3 & 2 & 1 & 2 & 3 & 1 & 585.6 & 0.4460 \\
\hline
\end{tabular}

TABLE 5: $S / N$ ratios of maximum stress and strain.

\begin{tabular}{|c|c|c|c|c|c|c|c|c|c|c|}
\hline Sets number & A & B & $\mathrm{C}$ & $\mathrm{D}$ & $\mathrm{E}$ & $\mathrm{F}$ & G & $\mathrm{H}$ & Maximum stress & Maximum strain \\
\hline 1 & 1 & 1 & 1 & 1 & 1 & 1 & 1 & 1 & -52.744 & 10.522 \\
\hline 2 & 1 & 1 & 2 & 2 & 2 & 2 & 2 & 2 & -55.738 & 7.797 \\
\hline 3 & 1 & 1 & 3 & 3 & 3 & 3 & 3 & 3 & -53.242 & 8.857 \\
\hline 4 & 1 & 2 & 1 & 1 & 2 & 2 & 3 & 3 & -53.618 & 10.150 \\
\hline 5 & 1 & 2 & 2 & 2 & 3 & 3 & 1 & 1 & -53.866 & 9.943 \\
\hline 6 & 1 & 2 & 3 & 3 & 1 & 1 & 2 & 2 & -54.791 & 8.664 \\
\hline 7 & 1 & 3 & 1 & 2 & 1 & 3 & 2 & 3 & -52.955 & 10.297 \\
\hline 8 & 1 & 3 & 2 & 3 & 2 & 1 & 3 & 1 & -55.388 & 9.794 \\
\hline 9 & 1 & 3 & 3 & 1 & 3 & 2 & 1 & 2 & -53.543 & 7.763 \\
\hline 10 & 2 & 1 & 1 & 3 & 3 & 2 & 2 & 1 & -53.109 & 7.715 \\
\hline 11 & 2 & 1 & 2 & 1 & 1 & 3 & 3 & 2 & -53.358 & 10.469 \\
\hline 12 & 2 & 1 & 3 & 2 & 2 & 1 & 1 & 3 & -55.919 & 8.478 \\
\hline 13 & 2 & 2 & 1 & 2 & 3 & 1 & 3 & 2 & -54.129 & 6.124 \\
\hline 14 & 2 & 2 & 2 & 3 & 1 & 2 & 1 & 3 & -53.829 & 9.754 \\
\hline 15 & 2 & 2 & 3 & 1 & 2 & 3 & 2 & 1 & -53.315 & 10.368 \\
\hline 16 & 2 & 3 & 1 & 3 & 2 & 3 & 1 & 2 & -53.210 & 10.397 \\
\hline 17 & 2 & 3 & 2 & 1 & 3 & 1 & 2 & 3 & -53.464 & 10.472 \\
\hline 18 & 2 & 3 & 3 & 2 & 1 & 2 & 3 & 1 & -55.352 & 7.013 \\
\hline
\end{tabular}

Table 7 expresses the quality characteristic (strain) which was obtained from actual experiment. The factor response table (Table 8) and graph (Figure 4) of the quality characteristic can be made according to the experimental data. Tables 6 and 8 indicated that factor $\mathrm{D}$ was the second most effective factor for strain and the most effective factor for quality characteristic, because it had the highest level difference among all control factors.

The optimal combination of bending parameters for minimizing strain was A1B3C2D1E2F3G1H3. The optimal 
TABLE 6: Response table for $S / N$ ration of strain.

\begin{tabular}{lcccccccc}
\hline Level & $\mathrm{A}$ & $\mathrm{B}$ & $\mathrm{C}$ & $\mathrm{D}$ & $\mathrm{E}$ & $\mathrm{F}$ & $\mathrm{G}$ \\
\hline 1 & 9.31 & 8.973 & 9.201 & 9.957 & 9.453 & 9.009 & 9.476 \\
2 & 8.977 & 9.167 & 9.705 & 8.275 & 9.498 & 8.366 & 9.219 & 8.226 \\
3 & - & 9.29 & 8.524 & 9.197 & 8.479 & 10.055 & 8.735 \\
Effect & 0.333 & 0.317 & 1.181 & 1.682 & 1.019 & 1.69 & 0.742 \\
Rank & 7 & 8 & 3 & 2 & 5 & 1 & 6.668 \\
\hline
\end{tabular}

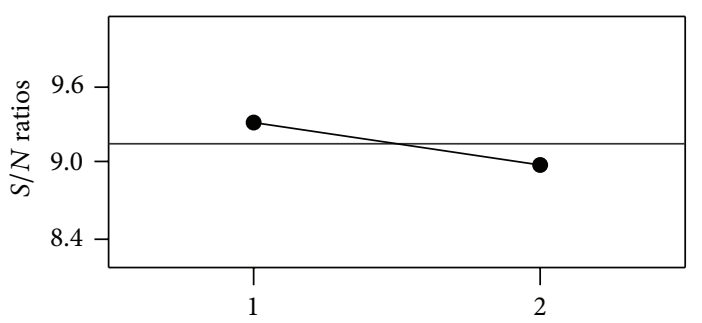

A

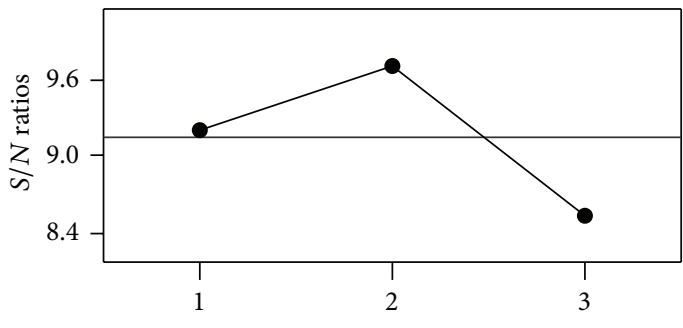

$\mathrm{C}$
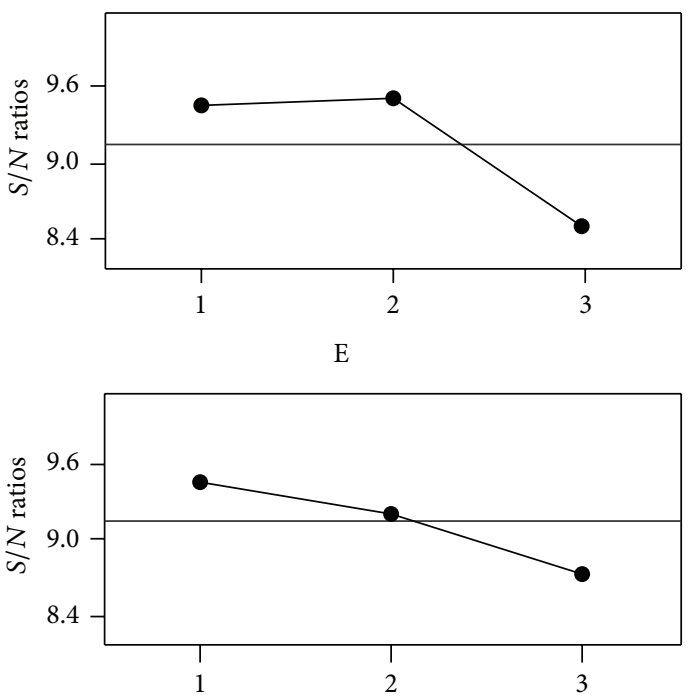

Signal-to-noise: smaller is better

G
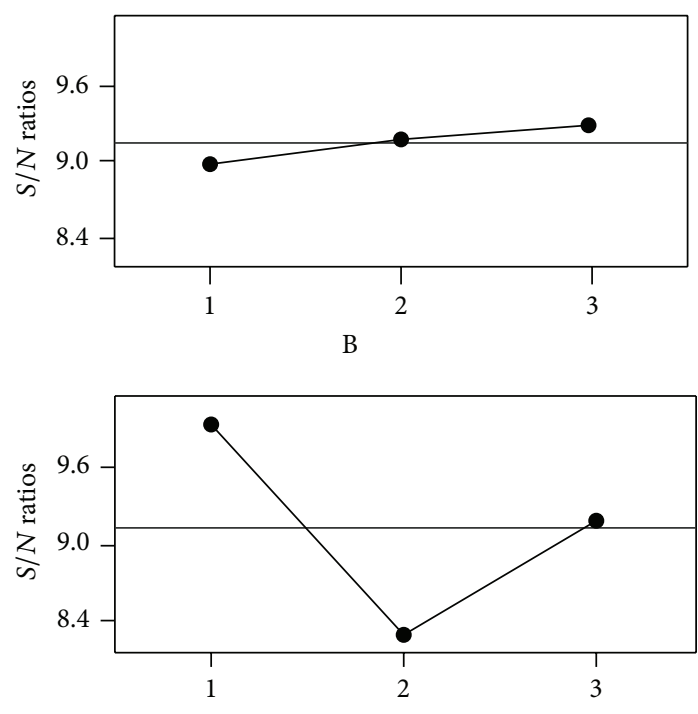

$\mathrm{D}$
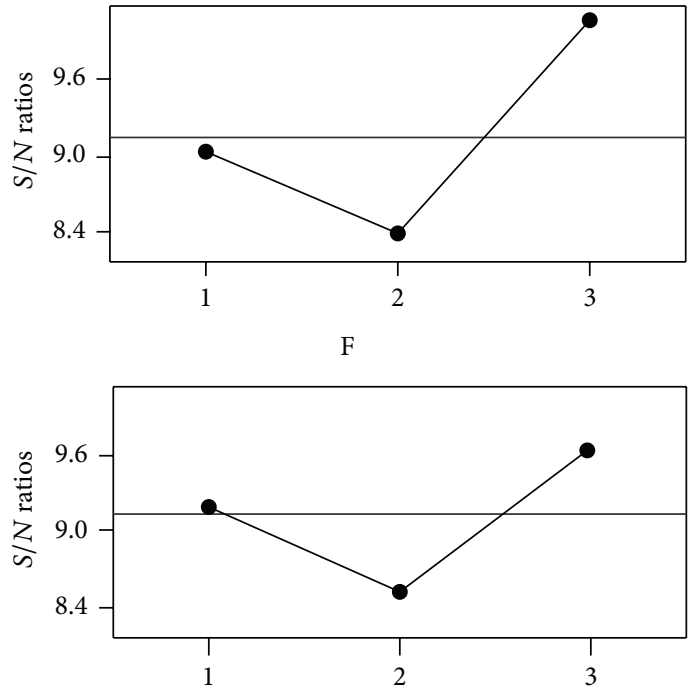

Signal-to-noise: smaller is better

$\mathrm{H}$

FIGURE 3: Response diagram of strain.

combination of bending parameters for quality characteristics was A2B3C2D1E2F3G1H3. The level of factor A (feed stroke) was the only difference, and A2 was selected for the sake of productivity. The optimum parameters were listed in Table 9.
The optimal parameters were reused through CAE analysis to obtain the maximum stress of $503.5 \mathrm{MPa}$ and maximum plastic strain of 0.327 . A comparison was made between these two values and the average values of 18 sets of data (Table 4). The results indicated that the maximum stress of $503.5 \mathrm{Mpa}$ 
TABLE 7: Strain of actual experiment.

\begin{tabular}{lccccccc}
\hline Sets number & $y 1$ & $y 2$ & $y 3$ & $y 4$ & $y 5$ & $y 6$ & 0.2978 \\
\hline 1 & 0.1765 & 0.2384 & 0.2782 & 0.2974 & 0.2978 & 0.4075 & 0.2644 \\
2 & 0.1799 & 0.2507 & 0.2938 & 0.3084 & 0.3093 & 0.2916 \\
3 & 0.1836 & 0.2506 & 0.2999 & 0.3159 & 0.3978 & 0.3607 & 0.3108 \\
4 & 0.1802 & 0.2404 & 0.2839 & 0.3062 & 0.3083 & 0.3183 & 0.2716 \\
5 & 0.184 & 0.2468 & 0.2861 & 0.3051 & 0.3055 & 0.3688 \\
6 & 0.1832 & 0.2407 & 0.2891 & 0.367 & 0.3686 & 0.3056 \\
7 & 0.1781 & 0.2421 & 0.2855 & 0.3045 & 0.3056 & 0.3029 \\
8 & 0.1787 & 0.2435 & 0.2825 & 0.3214 & 0.3219 & 0.2702 \\
9 & 0.1812 & 0.2475 & 0.29 & 0.3077 & 0.3091 & 0.4091 \\
10 & 0.175 & 0.2413 & 0.2792 & 0.2978 & 0.2984 & 0.4114 & 0.2786 \\
11 & 0.1795 & 0.235 & 0.2763 & 0.2975 & 0.2982 & 0.2996 \\
12 & 0.1774 & 0.2401 & 0.2712 & 0.2912 & 0.2917 & 0.3768 \\
13 & 0.1734 & 0.2414 & 0.2787 & 0.3388 & 0.339 & 0.2908 \\
14 & 0.1803 & 0.2443 & 0.2849 & 0.3229 & 0.3243 & 0.2644 \\
15 & 0.1815 & 0.2387 & 0.2761 & 0.3007 & 0.3011 & 0.2747 \\
16 & 0.1799 & 0.2448 & 0.2839 & 0.3003 & 0.3005 & 0.3031 \\
17 & 0.1767 & 0.238 & 0.2776 & 0.2974 & 0.2974 & 0.3021 \\
18 & 0.1801 & 0.2419 & 0.2816 & 0.295 & 0.2959 & 0.2995 \\
\hline
\end{tabular}

TABLE 8: Response table for actual experiment of strain.

\begin{tabular}{lcccccccc}
\hline Level & $\mathrm{A}$ & $\mathrm{B}$ & $\mathrm{C}$ & $\mathrm{D}$ & $\mathrm{E}$ & $\mathrm{F}$ & $\mathrm{G}$ \\
\hline 1 & 0.2829 & 0.28 & 0.2783 & 0.2704 & 0.2787 & 0.2827 & 0.2755 & 0.2763 \\
2 & 0.2782 & 0.2845 & 0.2756 & 0.2853 & 0.2753 & 0.2847 & 0.28 & 0.2882 \\
3 & & 0.2771 & 0.2878 & 0.286 & 0.2876 & 0.2743 & 0.2862 & 0.2771 \\
Effect & 0.0046 & 0.0074 & 0.0122 & 0.0156 & 0.0123 & 0.0104 & 0.0107 & 0.0118 \\
Rank & 8 & 7 & 3 & 1 & 2 & 6 & 5 \\
\hline
\end{tabular}

was very close to the average stress of $503.1 \mathrm{Mpa}$ obtained from the Taguchi method of 18 sets of data, and maximum strain of 0.327 was lower than the average strain of 0.353 obtained from the Taguchi method of 18 sets of data, and it can be made sure that the Taguchi method selected optimal parameters are correct.

A confirmation test was done after the optimal combination of process parameters was determined. The measure point of strain obtained by finite element analysis is near the bending radius of the tube; the strain value is 0.1342 , as shown in Figure 5. At the same position, the strain obtained by actual tube bending experiments using strain gauges is 0.1428 . The results indicate that the error between confirmation test and actual experiment is $6.39 \%$ (Table 10 ).

The completed workpiece using optimal parameters is shown in Figure 6. The surface around the curved corner of the optimum workpiece is obviously smoother than the original workpiece.

\section{Conclusion}

The CNC bending parameters were selected as Taguchi experimental factors rather than bending radius. This is because the actual bending process had to consider operation convenience. The results show that the selected optimum parameters can actually apply to bending operation without further conversion. The experimental results may be summarized as follows.

(1) According to response diagram, factor D (rotation axis $B$ stroke 2 ) is the most effective process factor. The level of this factor should be smaller to avoid product failure. 


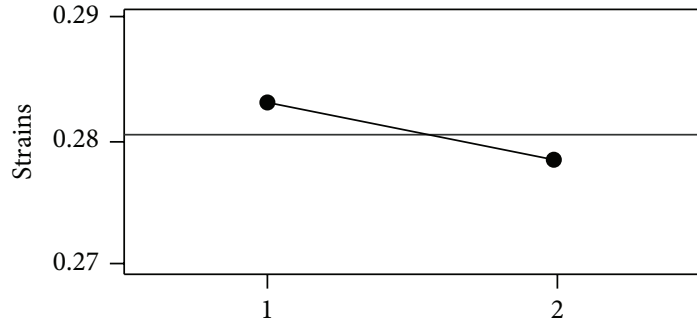

A

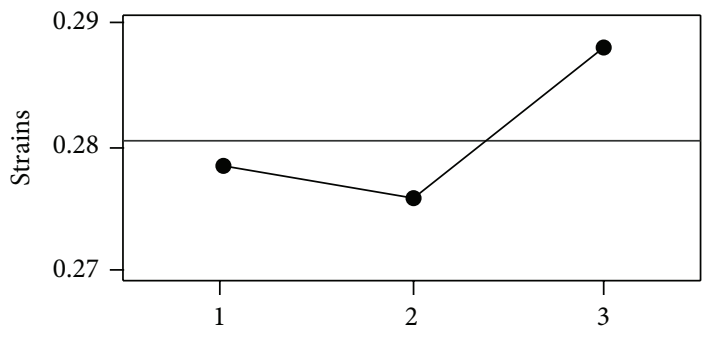

C

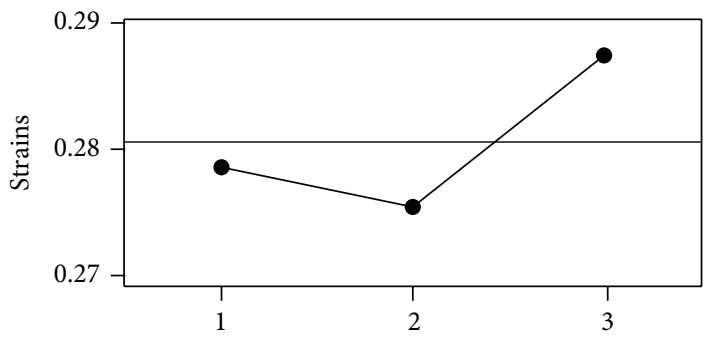

E

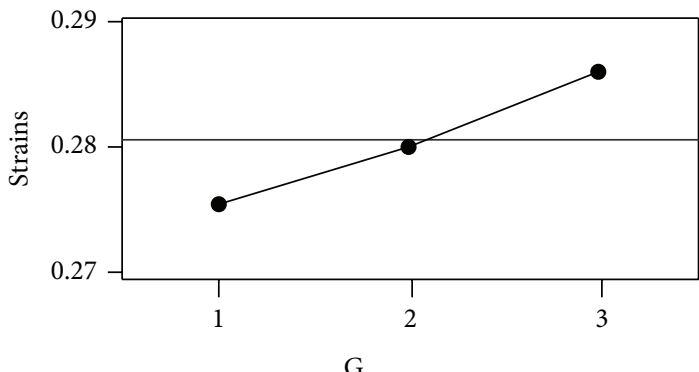

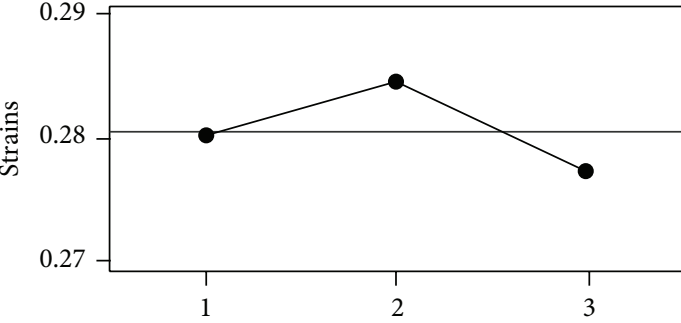

B

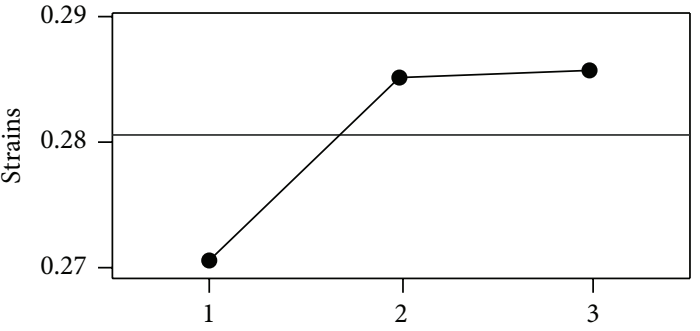

$\mathrm{D}$

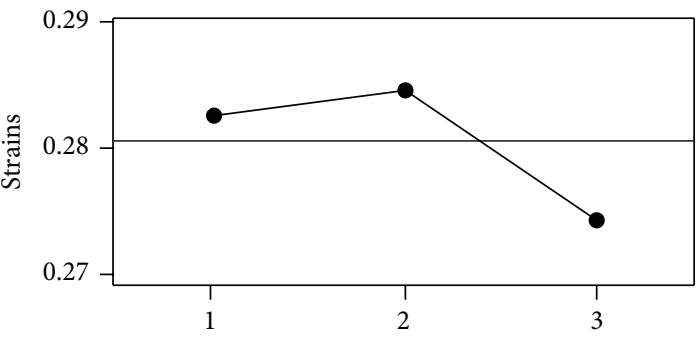

F

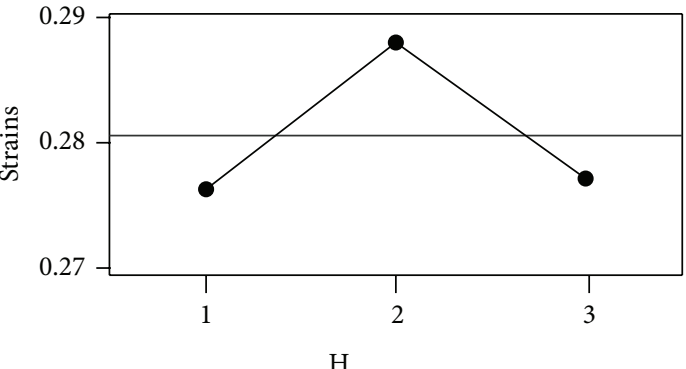

FIgURE 4: Response diagram of quality characteristics.

TABLE 9: Optimal bending parameters.

\begin{tabular}{lccc}
\hline & Feeding axis $Y$ & Rotation axis $B$ & Bending axis $C$ \\
\hline Stroke 1 & $140 \mathrm{~mm}$ & $-250^{\circ}$ & $46.5^{\circ}$ \\
Stroke 2 & $140 \mathrm{~mm}$ & $-225^{\circ}$ & $46.5^{\circ}$ \\
Stroke 3 & $120 \mathrm{~mm}$ & $-80^{\circ}$ & $49^{\circ}$ \\
\hline
\end{tabular}

TABLE 10: Comparison between experiment and simulation.

\begin{tabular}{lcc}
\hline & & Strain $(\mathrm{mm} / \mathrm{mm})$ \\
\hline Simulation & & 0.1342 \\
Actual experiment & Error $=6.39 \%$ & 0.1428 \\
& & \\
\hline
\end{tabular}

(2) The optimal bending parameters for minimizing maximum strain are A2, B3, C2, D1, E2, F3, G1, and $\mathrm{H} 3$. They are as follows: feed strokes 1 and $2=140 \mathrm{~mm}$; feed stroke $3=120 \mathrm{~mm}$; rotation stroke $1=-250^{\circ}$; rotation stroke $2=-225^{\circ}$; rotation stroke $3=-80^{\circ}$; bending stroke $1=46.5^{\circ}$; bending stroke $2=46.5^{\circ}$; and bending stroke $3=49^{\circ}$.

(3) The optimal parameters were utilized to execute a confirmation experiment, the results of which indicate that the strain error between experiment and FEM simulation is $6.39 \%$. 


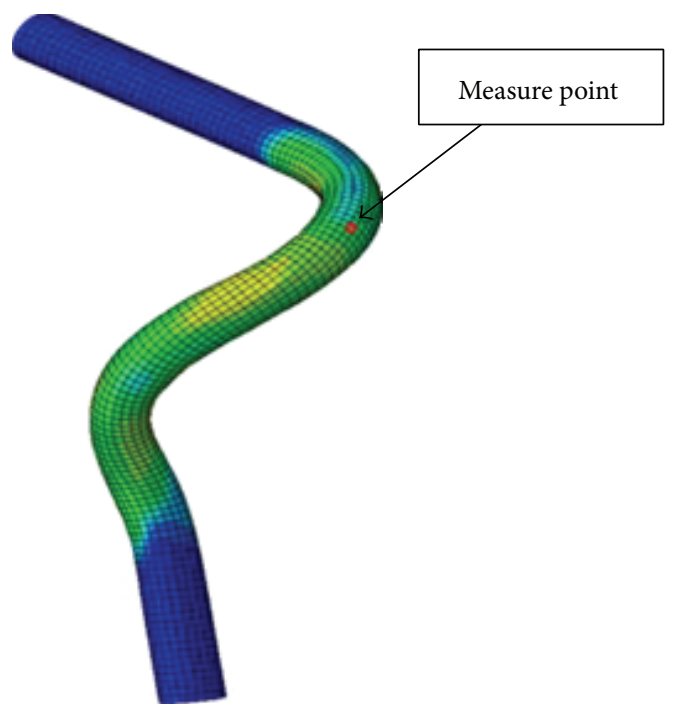

FIGURE 5: Measure point of FEM analysis.

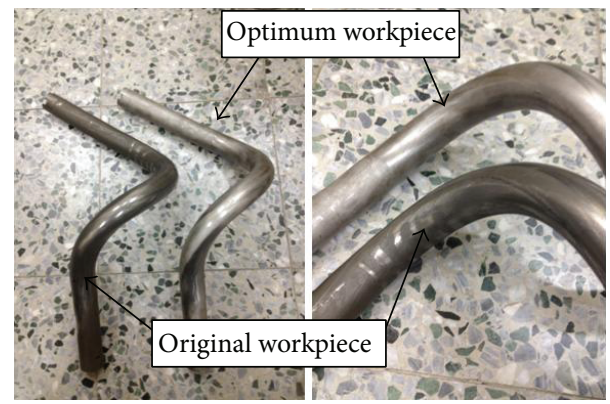

Figure 6: Comparison of workpiece.

\section{Conflict of Interests}

The authors declare that there is no conflict of interests regarding the publication of this paper.

\section{References}

[1] F. Stachowicz, "Bending with upsetting of copper tube elbows," Journal of Materials Processing Technology, vol. 100, no. 1, pp. 236-240, 2000

[2] L. G. Brazier, "On the flexure of thin cylindrical shells and other 'Thin' sections," Proceedings of the Royal Society of London A, vol. 116, pp. 104-114, 1927.

[3] P. K. Shaw and S. Kyriakides, "Inelastic analysis of thin-walled tubes under cyclic bending," International Journal of Solids and Structures, vol. 21, no. 11, pp. 1073-1100, 1985.

[4] S. Kyriakides and P. K. Shaw, "Inelastic buckling of tubes under cyclic bending," Journal of Pressure Vessel Technology, vol. 109, no. 2, pp. 169-178, 1987.

[5] F. Vollertsen, A. Sprenger, J. Kraus, and H. Arnet, "Extrusion, channel, and profile bending: a review," Journal of Materials Processing Technology, vol. 87, no. 1-3, pp. 1-27, 1999.

[6] H. M. Mourad and M. Y. A. Younan, "The effect of modeling parameters on the predicted limit loads for pipe bends subjected to out-of-plane moment loading and internal pressure," Transactions of the ASME, Journal of Pressure Vessel Technology, vol. 122, no. 4, pp. 450-456, 2000.

[7] H. M. Mourad and M. Y. A. Younan, "Nonlinear analysis of pipe bends subjected to out-of-plane moment loading and internal pressure," Journal of Pressure Vessel Technology, vol. 123, no. 2, pp. 253-258, 2001.

[8] A. Mentella and M. Strano, "Rotary draw bending of small diameter copper tubes: predicting the quality of the crosssection," Proceedings of the Institution of Mechanical Engineers Part B: Journal of Engineering Manufacture, vol. 226, no. 2, pp. 267-278, 2012.

[9] F. Paulsen and T. Welo, "Application of numerical simulation in the bending of aluminium-alloy profiles," Journal of Materials Processing Technology, vol. 58, no. 2-3, pp. 274-285, 1996.

[10] E. Bagci and Ş. Aykut, "A study of Taguchi optimization method for identifying optimum surface roughness in CNC face milling of cobalt-based alloy (stellite 6)," The International Journal of Advanced Manufacturing Technology, vol. 29, no. 9-10, pp. 940947, 2006.

[11] N. Alagumurthi, K. Palaniradja, and V. Soundararajan, "Optimization of grinding process through Design of Experiment (DOE) - a comparative study," Materials and Manufacturing Processes, vol. 21, no. 1, pp. 19-21, 2006.

[12] M. S. Phadke, Quality Engineering Using Robust Design, Prentice Hall, Englewood Cliffs, NJ, USA, 1989.

[13] H. H. Lee, Taguchi Method, Quality Characteristics Concept and Practices, GaoLi Books, Taipei, Taiwan, 2005. 

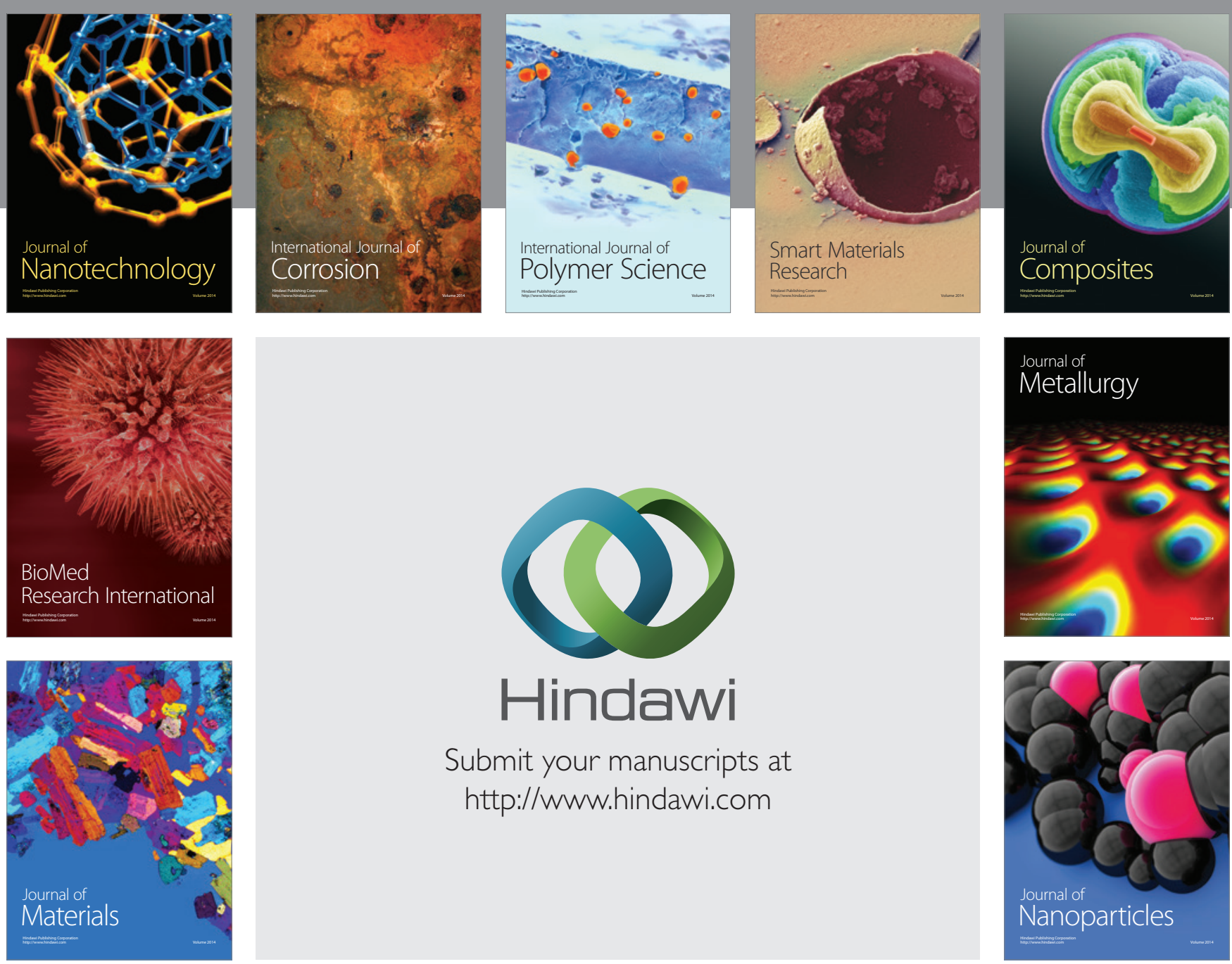

Submit your manuscripts at http://www.hindawi.com
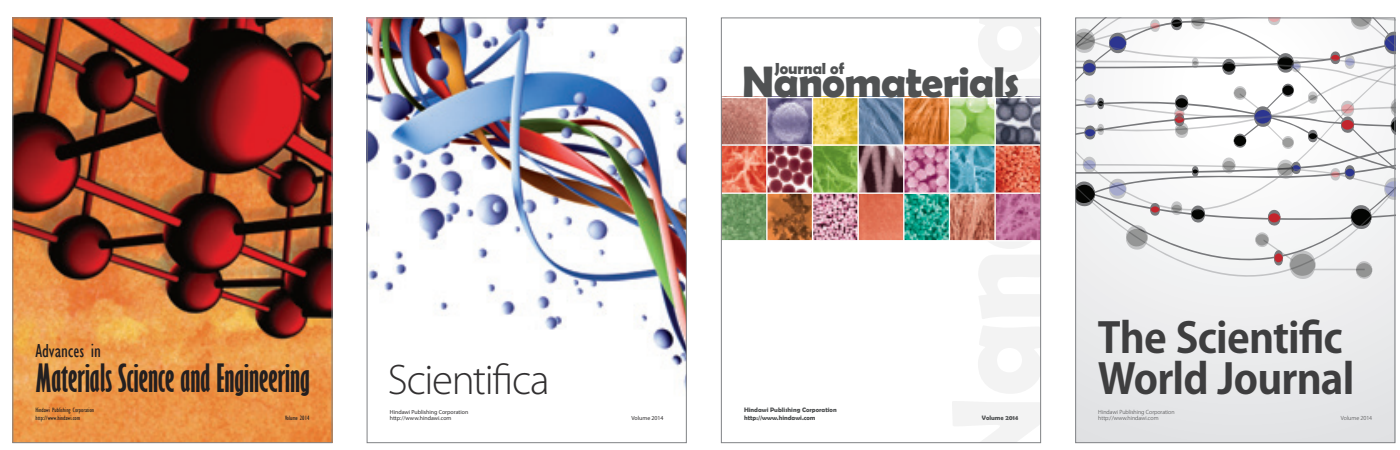

\section{The Scientific World Journal}
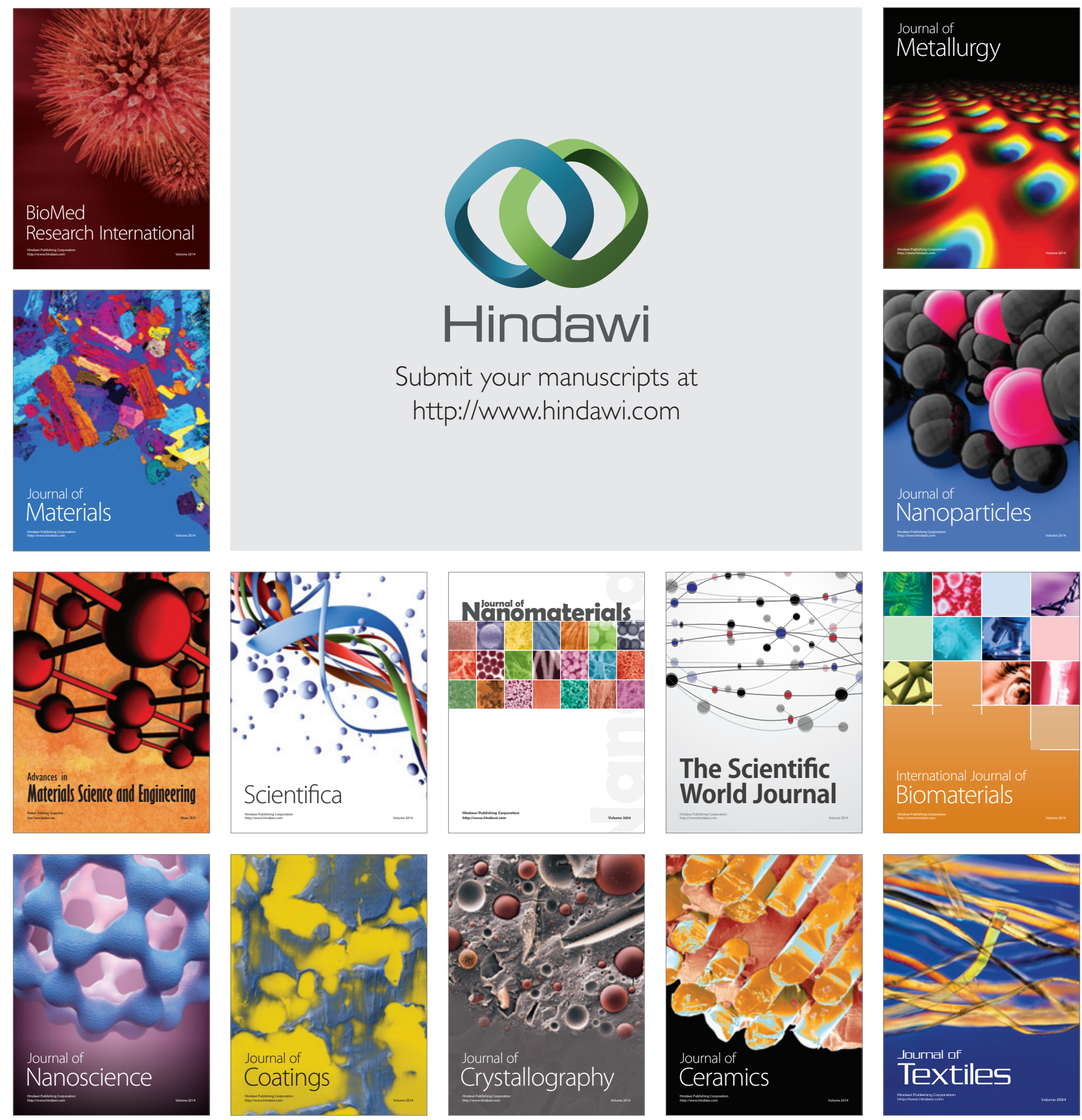